\title{
Periodical, Neurological-functional Assessment for Cervical Cord Injury
}

\author{
S. Tominaga, MD \\ Department of Orthopaedic Surgery, Shimane Prefectural Central Hospital, \\ Izumo City, Fapan.
}

\section{Summary}

The residual, reversible potentials of neurological-functional recovery in patients paralysed due to a cervical cord injury were periodically checked according to the various assessment methods from the initial period of 72 hours after injury to the final follow-up of 7 years.

In our series, the data on the neurological changes were a little different from those reported in the literature.

In the complete paralysis group, only 2 of the 30 patients showed slight functional recovery of less than 1 grade in the Frankel classification with descent of the cord lesion level. Twenty three patients showed descent of a half to one segment from the initial cord lesion level. The remaining 5 patients deteriorated because of ascent of a half to two segments from the initial cord lesion level. All patients with complete paralysis remained essentially unchanged.

In the incomplete group, 58 of the 70 patients had significant recovery of more than 1 grade in the Frankel classification. The grade of neurological recovery was different in each patient. Patients with a central cord lesion showed remarkably better recovery of the cord function than those with other types of cord lesions. Nineteen of the 49 patients with a central cord lesion regained independent walking ability with or without aid.

Neurological recovery in the incomplete paralysis group might be expected until approximately 6 months after injury. The early appearance of signs of recovery was an indication of better results. There was no difference in the neurological recovery between patients who had been realigned surgically and those who have been realigned non-surgically. Our neurological-functional assessment method reflecting the sectional and logitudinal cord level function and expressing more detailed information was demonstrated.

Magnetic resonance imaging (MRI) was used to assess residual cord function. The area of abnormal signal intensity almost corresponded to the cord level diagnosed neurologically.

Key words: Cervical cord injuries; Neuro-functional outcome; Transverse and longitudinal planes. 
Table I Pattern of cervical spinal injury

\begin{tabular}{|c|c|c|}
\hline \multicolumn{3}{|c|}{ Bony injury $n=50$ patients } \\
\hline \multicolumn{3}{|c|}{ Luxation (Lx) 30} \\
\hline Pattern I & $\begin{array}{l}\text { displaced less than the half of } \\
\text { vertebral breadth }\end{array}$ & 10 \\
\hline II & $\begin{array}{l}\text { displaced more than the half of } \\
\text { vertebral breadth }\end{array}$ & 20 \\
\hline \multicolumn{3}{|c|}{ Fracture (fx) 20} \\
\hline Pattern I & anteriorly compressed & 9 \\
\hline II & totally bursted & 10 \\
\hline III & laminal $\mathrm{fx}(1 \mathrm{~m}, \mathrm{fx})$ & 1 \\
\hline \multicolumn{3}{|c|}{ Non-bony injury $n=50$ patients } \\
\hline Pattern I & disc rupture (dc. rp) & 30 \\
\hline II & with OPLL & 10 \\
\hline III & spondylotic (spl) & 10 \\
\hline
\end{tabular}

The purpose of this study is to assess the residual, reversible functional potentials of neurological recovery in patients with complete and incomplete paralysis following cervical cord injury. These patients were checked periodically and classified according to various classification systems. (Stauffer et al., 1978; Schneider et al., 1954, 1955; Bosch et al., 1971; Frankel et al., 1969; Maynard et al., 1979; Zancolli, 1975).

The classifications in use did not always reflect the neurological status sufficiently because of their simplicity.

Our neurological-functional assessment method, reflecting the cross-sectional as well as the longitudinal cord level functions might be more useful for recording the information and for analysing the prognosis statistically.

The findings of conventional radiography and computed tomography at the initial period were compared with those of MRI at the recent follow-up. MRI offered more prognostic information. (Kalkarm et al., 1987; Kadoga et al., 1987; Mirvis et al., 1987, 1988).

\section{Material}

One hundred patients, 72 males and 28 females, who had been treated between 1970 and 1984 in our hospital were selected. The age ranged from 13 to 66 and the length of hospitalisation ranged from 6 months to 3 years. The patients selected were more than grade $\mathrm{C}$ in the Frankel classification, without serious head injury or serious associated complications, without prolonged respiratory problems; they have survived beyond 7 years and finally were all well documented. The patterns of cervical spinal injury were shown in Table I.

Fifty patients had bony injury. Intervertebral dislocation was seen in 30 patients and vertebral fracture in 20 . The remaining 50 patients had no bony injury; disc rupture in 30 , ossification of the posterior longitudinal ligament (OPLL) in 10 , and spondylosis in 10 .

Our classification was revised from those of Schneider and Bosch. Four basic types, reflecting the areas of cord lesion were classified. Each type was divided into 3 subtypes according to the severity of paralysis. These types and subtypes are shown in Table II. Type $\mathrm{V}$, indicating transverse cord lesion, is consistent 
Table II Classification (Shimane)

\begin{tabular}{|c|c|c|c|}
\hline Type & Cord lesion & Grade & Area of cord lesion \\
\hline I & Central & $\begin{array}{l}\text { a. slightly paralytic } \\
\text { b. moderately } \\
\text { c. severely }\end{array}$ & $\begin{array}{l}\text { initially spreading into the entire cord } \\
\text { and gradually decreasing in the central } \\
\text { area. grey matter, inner half of white } \\
\text { matter }\end{array}$ \\
\hline II & Anterolateral & $\begin{array}{l}\text { a. slightly paralytic } \\
\text { b. moderately } \\
\text { c. severely }\end{array}$ & $\begin{array}{l}\text { I }+ \text { spinothalamic tract (superficial } \\
\text { sensation) \& lateral pyramidal tract } \\
\text { (motor) }\end{array}$ \\
\hline III & Posterolateral & $\begin{array}{l}\text { a. slightly paralytic } \\
\text { b. moderately } \\
\text { c. severely }\end{array}$ & $\begin{array}{l}\text { I }+ \text { posterior column (deep sensation) } \\
\text { and outer pyramidal tract }\end{array}$ \\
\hline IV & Unilateral & $\begin{array}{l}\text { a. slightly paralytic } \\
\text { b. moderately } \\
\text { c. severely }\end{array}$ & hemisectional \\
\hline V & Transverse & $\begin{array}{l}\mathrm{b}=\text { almost complete } \\
\mathrm{c}=\text { complete paralysis }\end{array}$ & transectional \\
\hline
\end{tabular}

with complete paralysis. The other types are included in the incomplete paralysis group.

The level of injury in relation to the degree of cervical spinal injury was checked. The majority of the patients included had injuries to the middle and lower cervical region. The malalignment due to cervical spinal injury was reduced as early as possible within 24 hours after injury. Respiratory quadriplegia (Stauffer et al., 1978; Tominaga, 1981) involving C2-3 cord level was seen in 7 patients. Complete paralysis was seen in 4 and incomplete paralysis in 3.

Patients with complete respiratory paralysis were successfully weaned off the respirator within 3 months with descent of the cord lesion level. On the other hand, the patients with incomplete paralysis and respiratory problems at the initial period gradually regained diaphragmatic function.

\section{Methods}

The patients were analysed neurologically according to the Frankel, the Maynard, the Zancolli and our classification systems.

The neurological changes, the degree of paralysis and its characteristics were periodically checked at 72 hours, 6 months, 1 year and 7 years following the injury. The initial assessment was started not on admission but at 72 hours after injury.

\section{Results}

Neurological-functional changes in the paralytic grade were periodically checked. The relationship between cervical bony injuries and Frankel Grade is shown in Table III.

There was no difference in the degree of recovery of paralysis between the patients with bony injury and those with non-bony injury. The early reduction of malalignment may play an important role in preventing the cord lesion from extending upward and downward. The degree of paralysis at 72 hours and 1 
Table III Relation between cervical spinal injury and Frankel grade

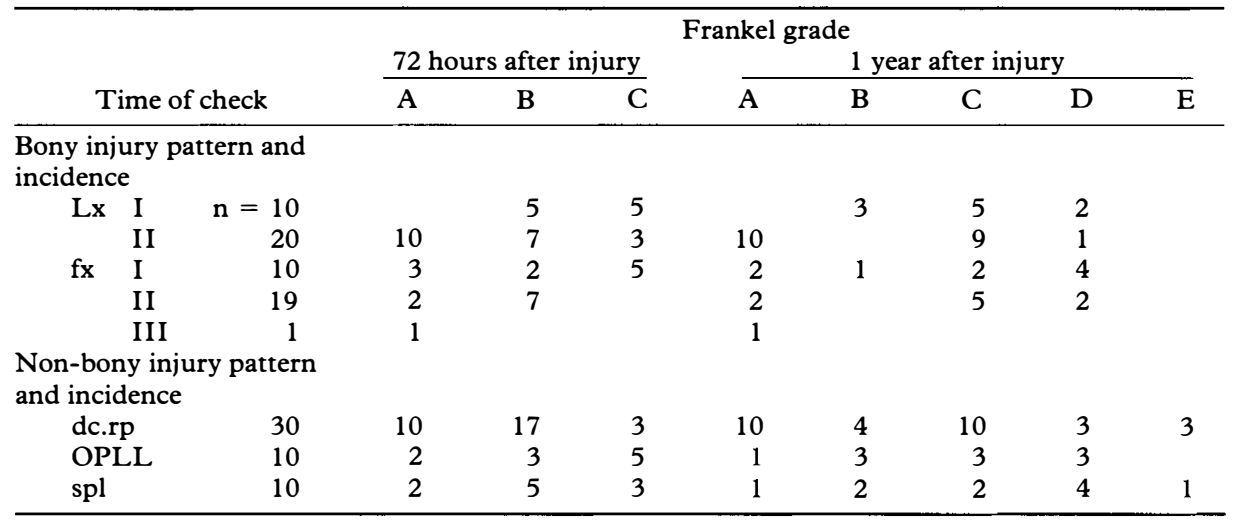

year after injury is shown in Table IV. In the complete paralysis group graded as A, only 2 of the 30 patients showed a slight functional recovery of less than 1 grade in the Frankel classification with descent from the initial cord lesion level. Twenty three patients had slight recovery of a half to one segment functon with descent from the initial cord lesion level. The remaining 5 patients had a half to two segments ascent from the initial cord lesion level. Twenty of 35 patients initially classified as Grade C may be graded between C and D. The incomplete paralysis group was classified according to Maynard et al. All of the 70 patients with Grade $S+M$ had significant recovery of more than a half or one grade.

Our classification type was checked in relation to the Frankel and Maynard Grade at 72 hours and 1 year after injury (Table V).

After 1 year, 1 of 9 patients classified as Type IIc (anterolateral cord lesion type, grade c) and 1 of 4 patients classified as Type IIIc (posterolateral cord lesion type, grade c) graded down from Type Vc (transverse cord lesion type, grade $\mathbf{c})$.

\section{Changes in our classification type}

The periodical changes were checked at initially 72 hour, 6 month, 1 year and finally 7 year intervals respectively according to our classification systems. These changes are shown in Table V.

In the incomplete paralysis group including three types except for tranverse cord lesion type, 58 of the 70 patients had significant recovery of more than 1 grade in the Frankel and the Maynard classification.

The patients with Type I (central cord lesion) with sparing of most laterally spaced fibres, showed remarkably better recovery of the cord function than those with Type II (anterolateral cord lesion) or Type III (Posterolateral cord lesion). Nineteen of the 49 patients with this type regained independant walking ability with or without any aid.

The patients with excessive spasticity had marked restricted functions in the arms and legs even if incompletely paralysed.

The patient with Type II or Type III, affecting the pyramidal tract and 
Table IV Change in Frankel grade and its incidence

\begin{tabular}{ccccccc}
\hline $\begin{array}{c}72 \text { hours after injury } \\
\text { Grade }\end{array}$ & A 28 & B 13 & C 36 & D 19 & E 4 \\
\hline A 30 & 28 & 1 & 1 & & \\
B 50 & & 12 & $35^{\star}$ & 2 & 1 \\
C 20 & & & & 17 & 3 \\
D 0 & & & & & \\
\hline
\end{tabular}

* 28 of 35 patients may be graded between Grades C and D.

Table $\mathbf{V}$ Change in our classification type

\begin{tabular}{|c|c|c|c|c|c|}
\hline \multicolumn{2}{|c|}{$\begin{array}{l}\text { Time of Check } \\
\text { Type }\end{array}$} & 72 hours & 6 months & 1 year & 7 years \\
\hline I & $=49$ & c 49 & $\begin{array}{lr}\text { a } & 4 \\
\text { b } & 15 \\
\text { c } & 30\end{array}$ & $\begin{array}{lr}\text { a } & 4 \\
\text { b } 17 \\
\text { c } 28\end{array}$ & $\begin{array}{lr}\text { a } & 4 \\
\text { b } & 17 \\
\text { c } & 26\end{array}$ \\
\hline I I & 8 & $\begin{array}{ll}\text { b } & 4 \\
\text { c } & 4\end{array}$ & $\begin{array}{ll}\text { b } & 4 \\
\text { c } & 5 \star\end{array}$ & $\begin{array}{ll}\text { c } & 4 \\
\text { b } & 5\end{array}$ & $\begin{array}{l}\text { b } \\
\text { c }\end{array}$ \\
\hline III & 10 & c 10 & b 6 * & b 11 & b 9 \\
\hline IV & 3 & c 3 & $\begin{array}{ll}\mathrm{a} & 2 \\
\mathrm{~b} & 1\end{array}$ & $\begin{array}{ll}\mathrm{a} & 2 \\
\mathrm{~b} & 1\end{array}$ & $\begin{array}{ll}\mathrm{a} & 2 \\
\mathrm{~b} & 1\end{array}$ \\
\hline V & 30 & c 30 & c 28 & c 28 & c 28 \\
\hline
\end{tabular}

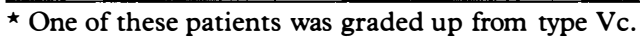

Table VI Change in Zancolli classification

\begin{tabular}{|c|c|c|c|}
\hline \multicolumn{4}{|c|}{$\begin{array}{l}\text { The lowest residual functional segment for complete paralysis and the } \\
\text { uppermost paralytic segment for incomplete paralysis * }\end{array}$} \\
\hline \multicolumn{2}{|c|}{72 hours after injury } & & 1 year after injury \\
\hline \multicolumn{2}{|c|}{ above C $3 n=7$} & 4 & C 3 \\
\hline $\mathrm{C} 4$ & 13 & ${ }^{3}{ }^{3}-^{3}=$ & C 4 \\
\hline $\mathrm{C} 5$ & 42 & $\longrightarrow{ }_{39}-1 \longrightarrow$ & C 5 A 7 \\
\hline C 6 & 33 & $=20-10 \square$ & $\begin{array}{r}\text { C } 6 \text { A } 10 \\
\text { B } 20\end{array}$ \\
\hline C 7 & 5 & 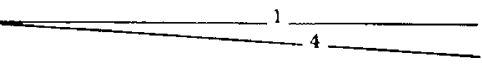 & $\begin{array}{rr}\mathrm{C} 7 \mathrm{~A} & 1 \\
\mathrm{~B} & 4\end{array}$ \\
\hline
\end{tabular}

^ Revised.

involving motor function, showed extremely poor recovery and none could walk independently. In the incomplete paralysis group, neurological recovery might not be expected until approximately 6 months after injury.

\section{Changes in Zancolli classification}

For complete paralysis, the most distal residual functional segment to the arms was neurologically examined. On the other hand, for incomplete paralysis, the uppermost affected segment to the arms was examined. The Zancolli level was checked at 72 hours and 1 year after injury. These changes are shown in Table VI. The paralytic changes due to upward extent of cord lesion level were noticed in 5 patients. The paralytic level in the other patients remained unchanged or descended to one or two segments. 


\section{Discussion}

As the time of initial assessment, we chose 72 hours after injury. The reason was to assess the paralytic status more exactly. In an emergency period, it is more difficult for us to perform an exact neurological examination because such patients are often unconscious and in a serious condition due to a head injury or other serious associated injury and complication. Therefore, the initial assessment should be performed at 72 hours after injury when the orthopaedic procedures would be finished and the general condition settled to some degree.

The patient assessed as having complete paralysis on admission might infrequently be incomplete at 72 hours after injury because of subsiding of diffusely extended cord oedema. This is the reason why our results are unfavourable, especially in the complete paralysis group and slightly different from the other reports on the prognosis of cervical cord injury (Bedbrook et al., 1980; Maynard et al., 1979; Merriam et al., 1986; Young et al., 1978-1979; Wilmot et al., 1986).

In our series, complete paralysis at 72 hours after injury remained almost unchanged at 6 months or 1 year. This may be correct judging from the cord pathology.

For the assessment of the longitudinal cord lesion level, the Stauffer classification system was used. For the assessment of the sectional damaged area, we used our classification system which is the revised Schneider and Bosch system. For the assessment of the severity of paralysis, we used both the Frankel and the Maynard classification systems, and for the assessment of the functional segment, the Zancolli classification system was used.

However, in any of these assessment methods, the paralytic state was difficult to assess accurately.

For neurological-functional assessment in cervical cord injury we want to assess the state of the paralytic condition in detail including the cord lesion level, the severity of symptoms and the characteristics of paralysis.

For example, the Frankel assessment method is reasonably graded on the basis of the neuropathology of cord injury, so that it is much more convenient to use and is generally accepted. However, the paralytic status of cervical cord lesion is not always reflected and expressed in detail because of its simplicity. Furthermore, between the patients classified as grade $\mathrm{C}$ or $\mathrm{D}$, there are many differences in neurological findings and functional degrees because grade $\mathrm{C}$ or $\mathrm{D}$ have the various severity of symptoms.

We propose an expression pattern as an assessment method, which is expressed in the letters and numbers (Table VII). This includes together the cord lesion level, the severity of paralysis and the characteristics of dysfunction. For example, 2 cases are shown in Figures 1 and 2. Case 1 had a compression fracture at $\mathrm{C} 5$ with a transverse cord lesion type at the initial assessment and after 7 years the paralytic status remained unchanged. The initial expression pattern, C5fxII.C5V5 changes finally into C5BVc.Eb.Wc. Case 2 had an interlocked dislocation at C6-7, which was operatively reduced immediately after injury. The initial pattern, C6-71xII.C6Vc, changed finally into C5B2Vc.Eb.Wc.

The initial letter indicates the site and status of vertebral injury, and the next expresses the lowest residual functional segment for complete paralysis and the 
A

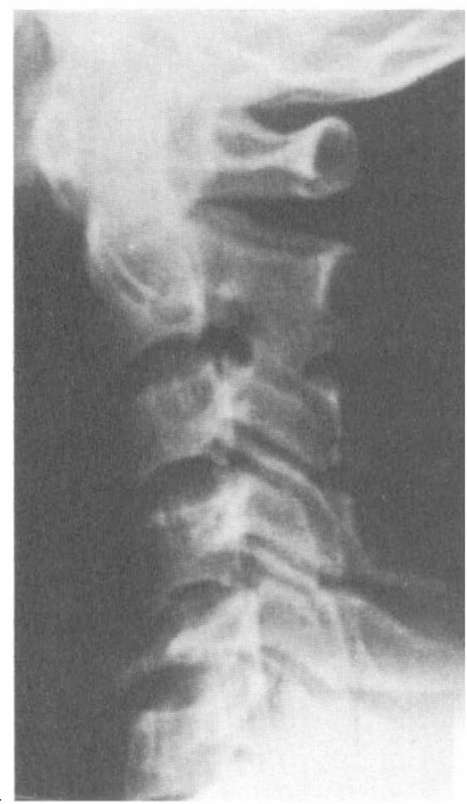

C

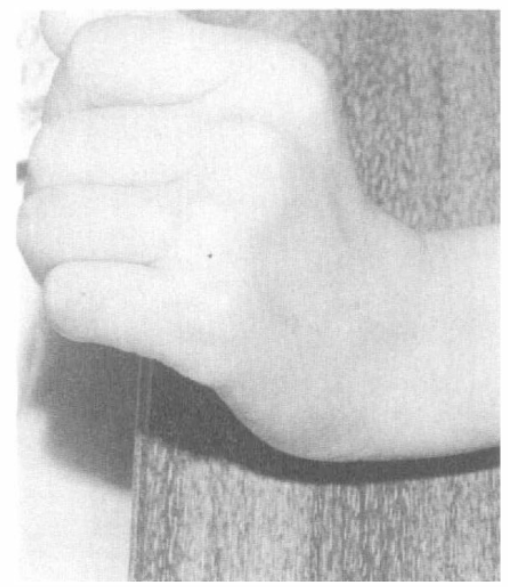

B

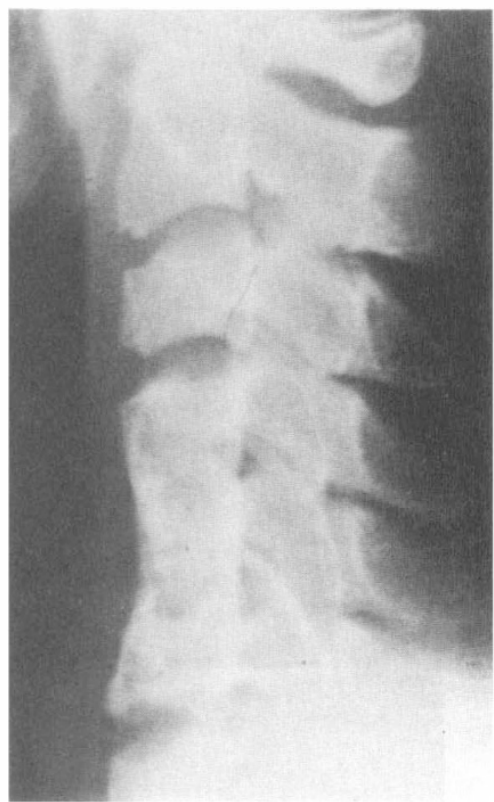

$\mathrm{D}$

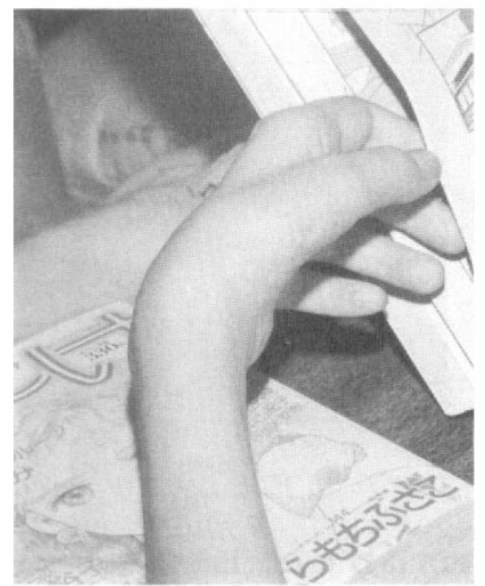

Figure 1A to D Case 1: Compression fracture at C5 with a transverse cord lesion.

uppermost paralytic segment for incomplete paralysis, and then the type of cord lesion, the degree of the severity of symptoms and at follow-up, eating ability and walking ability which are necessary in activities of daily living are expressed. The degree of eating and walking abilities is shown in Table VII.

More recently in 15 patients, we compared conventional radiograph and computed tomographs at the initial period of injury with MRI films at the follow-up. T1-weighted MRI was used to evaluate identation or morphologic changes in the cord. (Kulkarni et al., 1987; Mirvis et al., 1987, 1988).

The level of the cord was not always consistent with the level of the vertebral injury. It was frequently extended upward and downward a half to two cord segments. The upper border of the cord lesion delineated as a low signal in- 
A

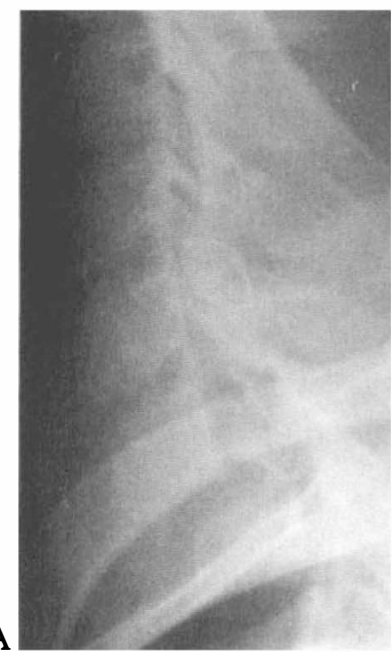

C

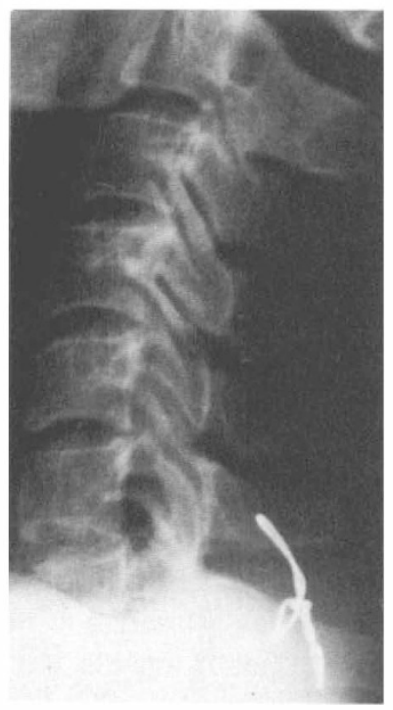

B

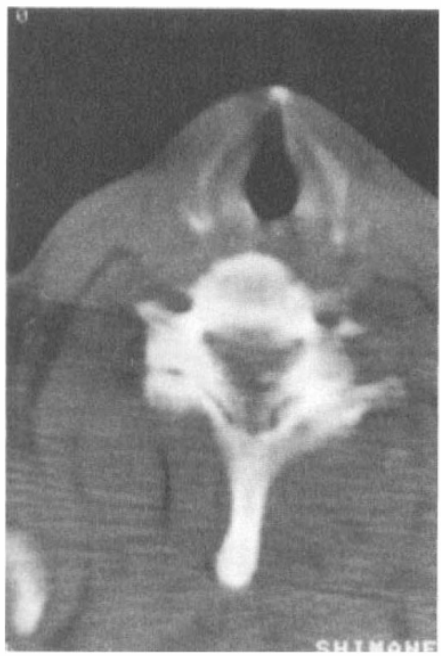

$\mathrm{D}$

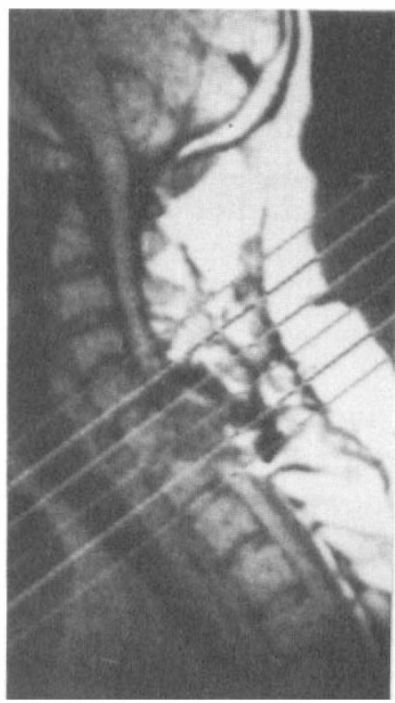

Figure 2A to D Case 2: Interlocked dislocation at C6-7.

Table VII Shimane neurological-functional assessment method for cervical cord injury

\begin{aligned} & \hline Expression pattern \\ & \hline Case 1 $\begin{array}{l}\text { initial pattern C5fxII.C5Vc } \\ \text { final pattern C5BVc.Eb.Wc } \\ \text { initial pattern C6-71xII.C6Vc } \\ \text { final pattern C5B2Vc.Eb.Wc }\end{array} \\ &$\hline $\begin{aligned} & \mathrm{Vc}= \text { severely paralytic transverse cord lesion } \\ & \mathrm{E}= \text { eating ability } \\ & \text { a. able to eat without aid } \\ & \text { b. able to eat with aid } \\ & \text { c. unable to eat even with aid } \\ & \mathrm{W}= \text { walking ability } \\ & \text { the same as described above }\end{aligned}\end{aligned}$




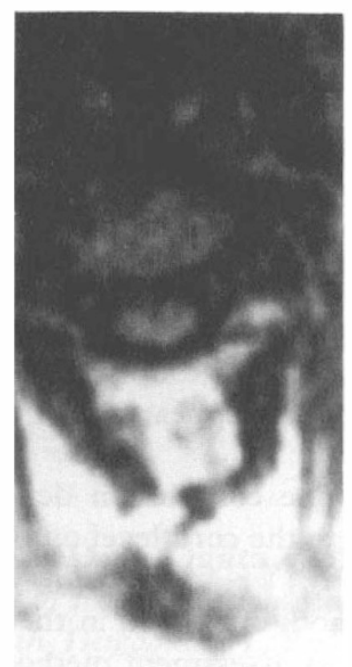

NAN

$\mathrm{E}$

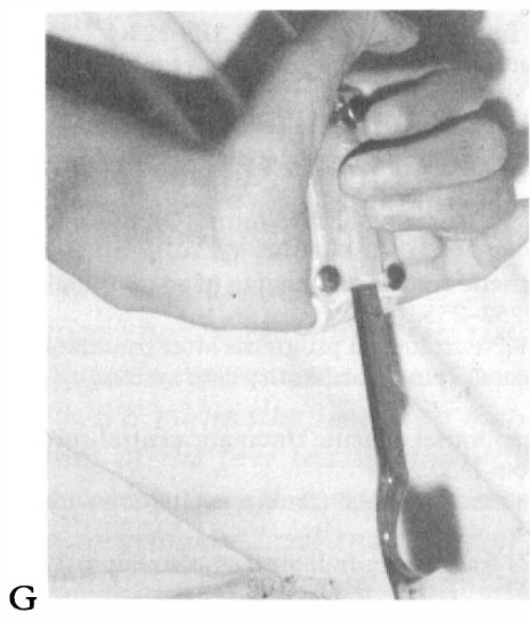

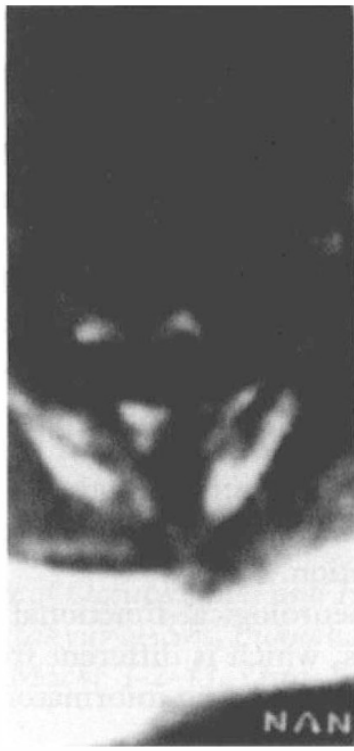

$\mathrm{F}$

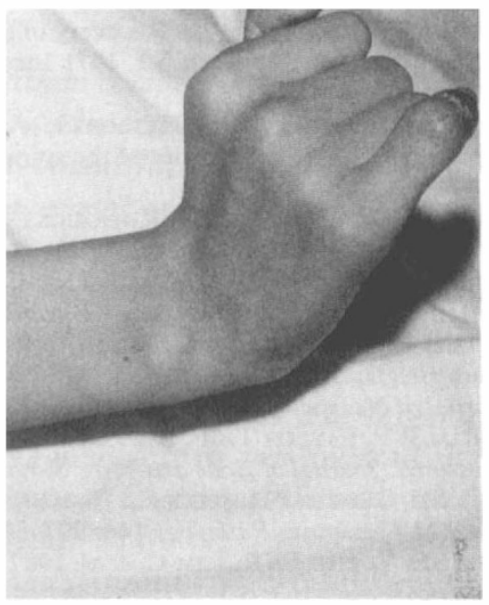

Figure 2E to $\mathbf{H}$ Case 2: Interlocked dislocation at C6-7.

tensity almost corresponded to the cord level diagnosed from the neurological examination. The information obtained from MRI may be more useful in assessment and the prospect of the prognosis for cervical cord injury.

\section{Conclusions}

In the complete paralysis group with complete loss of motor and sensory function at the initial 72 hours after injury, including the transverse cord lesion type alone, only 2 of the 30 patients showed slight recovery of less than 1 grade in the Frankel classification. Twenty three patients had more restricted recovery of a half to one segmental function with descent from the initial cord lesion level. The remaining 5 
patients, who were finally assessed as deteriorated, had upward extent of the paralytic level with ascent of a half to two segments from the initial cord lesion level.

In the incomplete paralysis group, including the other cord lesion types, 58 of the 70 patients had significant recovery of more than 1 grade in the Frankel and Maynard classificaton. In slight paralysis, cord function favourably recovered, while in severe paralysis it recovered slightly or remained unchanged. Twenty three patients had useful recovery of motor function grading according to the Frankel and the Maynard classification.

Neurological recovery in the incomplete paralysis group may be expected until approximately 6 months after injury. The early appearance of the signs of recovery led to rather better results.

MRI was used to evaluate cord function. The cord lesion detected as an abnormal signal intensity almost corresponded to the cord level on neurological examination.

Our neurological-functional assessment method, expressed in the letters and numbers, which is different from the other gross assessment methods, is more useful for recording informaton and for the statistical analysis of the prognosis.

\section{References}

BedBrook G, Hono STJ 1980 Recovery of spinal cord function. Paraplegia 18:315-323.

Bosch A, StaufFer S, NiCkel VL 1971 Incomplete traumatic quadriplegia, a ten year review. J $A M A$ 19:473-478.

FRANKel HL, HaNCOCK DO, Hyslop G, et al. 1969 The value of postural reduction in the initial management of closed injuries of the spine with paraplegia and tetraplegia, part I. Paraplegia 7:179-192.

Kulkarni MV, MCARdle CB, Kopanicky D, et al. 1987 Acute spinal cord injury: MRImaging a 1.5 T. Radiology 164:837-843.

Kadoga S, Nakamur T, Kobayashi S, et al. 1987 Magnetic resonance imaging of acute spinal cord injury, report of three cases. Neuroradiology 29:252-255.

MaynaRd FM, REYNOLDS GG, Fountain S, et al. 1979 Neurological prognosis after traumatic quadriplegia, three-year experience of California regional spinal cord injury care system.

fournal of Neurosurgery 50:611-616.

MERRIAM WF, FAYLOR TKF, RofF SJ, et al. 1986 A reappraisal of acute traumatic central cord syndrome. Fournal of Bone and foint Surgery 68-B:708-713.

Mirvis SE, GeIsLER FH, JELINECK JJ, et al. 1988 Acute cervical spinal trauma; evaluation with 1.5-T MRImaging. Radiology 166: 807-816.

MiRvis SE, Young JWR, Lim C, et al. 1987 Hangman's fracture; radiological assessment in 27 cases. Radiology 163:713-717.

SChNeIder RE, Cherry G, PANTek H 1954 The syndrome of acute central cervical spinal cord injury. Fournal of Neurosurgery 11:546-577.

SCHNEIDER RE 1955 The syndrome of acute anterior spinal cord injury, fournal of Neurosurgery 12:95-122.

STAUFFER ES, BeLl GD 1978 Traumatic respiratory quadriplegia and pentaplegia, Orthop Clin North Am, 9:1081-1088.

Tominaga S 1981 Pentaplegia and respiratory quadriplegia, Med f. Shimane Cent Hosp 8:19-31.

YOUNG JS, DExTER WR 1978-1979 Neurological recovery distal to the zone of injury in 172 cases of closed, traumatic spinal cord injury. Paraplegia 16:39-49.

Wilmot CB, HALL, KM 1986 Evaluation of acute management of tetraplegia; conservative versus surgical treatment. Paraplegia 24:148-156.

ZANCOLLI E 1975 Surgery for the quadriplegic hand with active, strong wrist extension preserved, a study of 97 cases. Clin Orthop $\mathcal{E}$ Related Research 112: 101-113. 